\title{
Pericardium Covered Stent Graft for Endovascular Treatment of a Traumatic Carotid-cavernous Fistula
}

\section{Sir,}

Direct carotid-cavernous fistulas (CCFs) are high-flow lesions which typically require intervention, due to the rapid progression of associated symptoms and their low rates of spontaneous resolution. ${ }^{[1]}$ Endovascular treatment is the mainstay of therapy for direct CCFs. ${ }^{[2]}$ The first-line endovascular approach for CCF is typically selective occlusion of the fistulous connection with coils or an embolic agent from either a transarterial or transvenous route. When selective embolization fails, covered stent grafts have been used as a potential salvage device for the treatment of persistent CCFs. ${ }^{[3]}$ However, there is limited data regarding the efficacy of covered stents for CCFs, and the role of these devices in the management of CCF patients is ill-defined. We describe a case of a traumatic, high-flow CCF which was treated with a pericardium covered stent graft.

A 20-year-old male suffered a penetrating injury to the left orbit after a motorcycle accident and was initially managed at an outside institution. The patient was found, on cerebral angiography, to have a traumatic dissection of the cavernous segment of the left internal carotid artery (ICA), with an associated pseudoaneurysm [Figure 1a and b]. The cavernous ICA dissection was stented, and the pseudoaneurysm was partially coiled at the outside institution [Figure 1c and d]. Follow-up angiography performed 6 days after the initial endovascular procedure showed interval development of a direct, high-flow CCF, and the patient was subsequently transferred to our center for further management.

The patient was taken our neurointerventional suite, where cerebral angiography confirmed the presence of a left-sided Barrow Type A direct CCF, with rapid shunting into the inferior petrosal sinuses bilaterally [Figure $2 \mathrm{a}$ and $\mathrm{b}$ ]. There was also very severe vasospasm of all the intracranial arteries, with very poor perfusion of the left hemisphere. Due to the angiographic appearance of the CCF and the deteriorating neurological status of the patient, we proceeded urgently with endovascular treatment. A 6-French (Fr) Neuron distal access catheter (Penumbra, Alameda, California, USA) was navigated into the preexisting stent that had herniated through the fistula into the left cavernous sinus. Next, a wire was maneuvered through the stent into the left angular artery. After an exchange wire was navigated into the angular artery, the prior stent was angioplastied with a Gateway Balloon (Boston Scientific, Natick, Massachusetts, USA) to tear the struts. This allowed passage of an Aneugraft D covered stent (EPS Vascular AB, Viken, Sweden) into the clinoidal segment of the left ICA. A construct comprised a $3.0 \mathrm{~mm} \times 13 \mathrm{~mm}$ and a $3.5 \mathrm{~mm} \times 18 \mathrm{~mm}$ Aneugraft

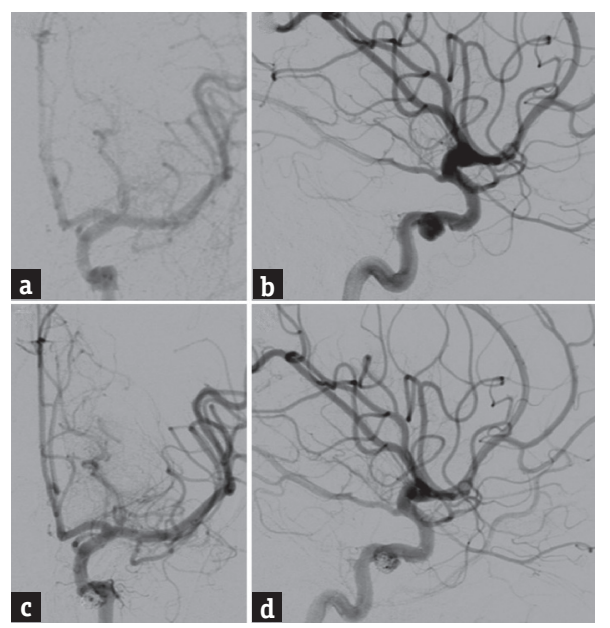

Figure 1: The initial cerebral angiography performed at an outside institution, (a) anteroposterior and (b) lateral views of a left internal carotid artery injection, showed a left cavernous internal carotid artery dissection with an associated pseudoaneurysm. The lesion was treated with stenting for the dissection and partial coil embolization of the pseudoaneurysm. Posttreatment angiography, (c) anteroposterior and (d) lateral views of a left internal carotid artery injection, showed successful stent-assisted coiling of the cavernous internal carotid artery dissection and pseudoaneurysm 
D covered stent was then formed back to the cavernous ICA, thereby excluding the fistula [Figure 2c].

The construct became narrowed after the two stent grafts were deployed, and an iatrogenic ICA dissection at its lacerum segment was incurred during the process of navigating the covered stent grafts through the preexisting stent. A $6.0 \mathrm{~mm} \times 22 \mathrm{~mm}$ Solitaire stent (ev3 Neurovascular, Irvine, California, USA) was deployed to pin the dissection in place. Poststenting angiography showed complete occlusion of the CCF, with preservation of flow through the ICA and improved perfusion of the left cerebral hemisphere [Figure 2c-e]. The diffuse vasospasm was angioplastied using a Copernic $4 \mathrm{~mm} \times 15 \mathrm{~mm}$ balloon (Balt Extrusion, Montmorency, France), which resulted in substantially improved vessel caliber. The patient was prescribed dual antiplatelet therapy, aspirin $100 \mathrm{mg}$, and clopidogrel $75 \mathrm{mg}$ daily, for 6 weeks after the stenting procedure.

Barrow et al. classified CCFs into four subtypes based on the angioarchitecture of the arteriovenous shunt. ${ }^{[1]}$ Type A CCFs are direct shunts between the cavernous ICA and cavernous sinus and are typically high-flow lesions which occur following trauma or cavernous ICA aneurysm rupture. Endovascular therapy is the treatment of choice for the majority of CCFs. Alternate treatment options, such as stereotactic radiosurgery, are generally less effective for high-flow fistulas and does not afford immediate obliteration. ${ }^{[4]}$ The goal of endovascular treatment is occlusion of the fistulous connection while preserving flow through the ICA. In some cases, ICA occlusion may be necessary to completely obliterate a $\mathrm{CCF}$, although this approach is not tolerated by all patients.

Covered stent grafts are not routinely used in the treatment of intracranial vascular disorders. As such, a wide range of devices has been employed. Lu et al. treated 32 patients with direct

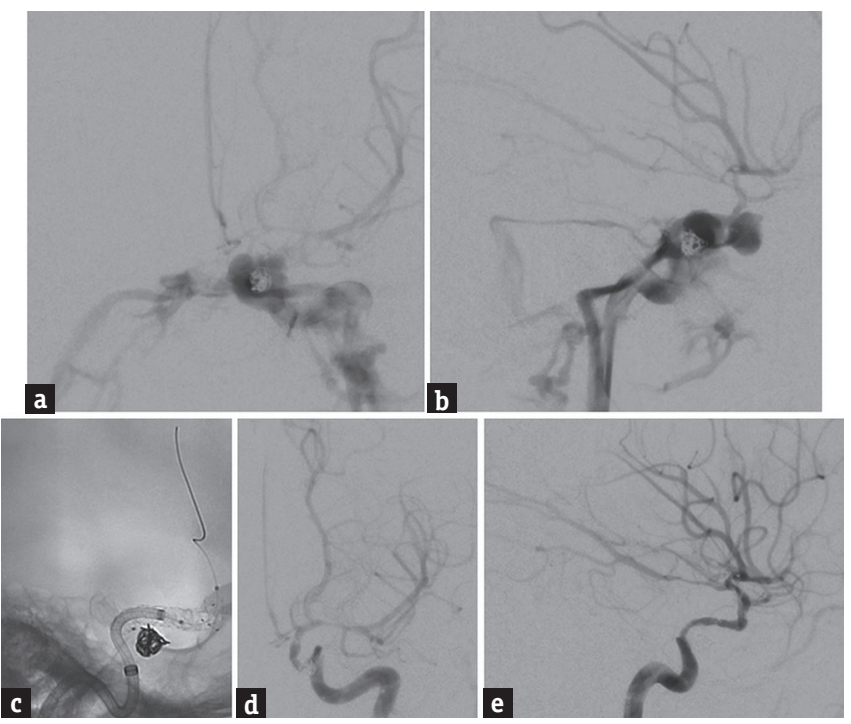

Figure 2: Follow-up cerebral angiography, (a) anteroposterior and (b) lateral views of a left internal carotid artery injection, shows the formation of a direct, high-flow carotid-cavernous fistula. The carotid-cavernous fistula was treated with overlapping covered stents. (c) Unsubtracted lateral view shows the stent construct. Angiography after stenting, poststenting angioplasty (Copernic $4 \mathrm{~mm} \times 15 \mathrm{~mm}$ balloon), and $5 \mathrm{mg}$ intra-arterial verapamil for vasospasm, (d) anteroposterior and (e) lateral views of a left internal carotid artery injection, shows complete occlusion of the carotid-cavernous fistula with preservation of flow through the internal carotid artery
CCFs, and used covered stents in only $6 \%$ of cases. ${ }^{[5]}$ We used a pericardium covered stent to successfully treated a traumatic Type A CCF which had failed prior stent-assisted coil embolization. Covered stents afford complete and immediate occlusion of a $\mathrm{CCF}$ while maintaining the patency of the ICA. For appropriately selected CCFs, particularly high-flow lesions and those which have failed conventional endovascular therapies, covered stents are a reasonable, vessel-preserving salvage treatment option.

\section{Financial support and sponsorship}

Nil.

\section{Conflicts of interest}

There are no conflicts of interest.

\section{Dale Ding ${ }^{1,2}$, Robert M. Starke ${ }^{3}$, Maurice Moriarty, Stefan Brew ${ }^{4}$}

${ }^{1}$ Department of Neurosurgery, University of Virginia, Charlottesville, VA 22908, ${ }^{3}$ Department of Neurological Surgery,

University of Miami, Miami, FL 33136, USA, Departments of ${ }^{2}$ Neurosurgery and ${ }^{4}$ Radiology, Auckland City Hospital, Auckland 1142, New Zealand

Address for correspondence: Dr. Dale Ding, Department of Neurosurgery, University of Virginia, P. O. Box: 800212, Charlottesville, VA 22908, USA. E-mail:dmd7q@hscmail.mcc.virginia.edu

\section{REFERENCES}

1. Barrow DL, Spector RH, Braun IF, Landman JA, Tindall SC, Tindall GT. Classification and treatment of spontaneous carotid-cavernous sinus fistulas. J Neurosurg 1985;62:248-56.

2. Phatouros CC, Meyers PM, Dowd CF, Halbach VV, Malek AM, Higashida RT. Carotid artery cavernous fistulas. Neurosurg Clin N Am 2000;11:67-84, viii.

3. Redekop G, Marotta T, Weill A. Treatment of traumatic aneurysms and arteriovenous fistulas of the skull base by using endovascular stents. J Neurosurg 2001;95:412-9.

4. Chen CJ, Lee CC, Ding D, Starke RM, Chivukula S, Yen CP, et al. Stereotactic radiosurgery for intracranial dural arteriovenous fistulas: Asystematic review. J Neurosurg 2015;122:353-62.

5. Lu X, Hussain M, Ni L, Huang Q, Zhou F, Gu Z, et al. A comparison of different transarterial embolization techniques for direct carotid cavernous fistulas: A single center experience in 32 patients. J Vasc Interv Neurol 2014;7:35-47.

This is an open access article distributed under the terms of the Creative Common Attribution-NonCommercial-ShareAlike 3.0 License, which allows others to remix, tweak, and build upon the work non-commercially, as long as the author is credited and the new creations are licensed under the identical terms.

\begin{tabular}{|l|l|}
\hline \multicolumn{2}{|c|}{ Access this article online } \\
\hline Quick Response Code: & Website: \\
\hline
\end{tabular}

How to cite this article: Ding D, Starke RM, Moriarty M, Brew S. Pericardium covered stent graft for endovascular treatment of a traumatic carotid-cavernous fistula. J Neurosci Rural Pract 2016;7:S137-8. 